\title{
Subclinical hypothyroidism and vascular risk: An update
}

\author{
Eirini Lioudaki, ${ }^{1}$ Niki G. Mavroeidi, ${ }^{1}$ Dimitri P. Mikhailidis, ${ }^{2}$ Emmanouel S. Ganotakis ${ }^{1}$ \\ ${ }^{1}$ Department of Internal Medicine, University of Crete and School of Medicine, Heraklion, Greece, ${ }^{2}$ Department of \\ Clinical Biochemistry (Vascular Disease Prevention Clinics), Royal Free Hospital campus, University College London \\ Medical School, University College London (UCL), London NW3 2QG, UK
}

\begin{abstract}
Subclinical hypothyroidism (SCH), defined as elevated serum thyroid-stimulating hormone (TSH) in the presence of normal circulating free thyroxine (FT4) and triiodothyronine (T3), is a relatively common condition. Replacement treatment with levothyroxine is justified only for individuals with TSH levels $>10 \mathrm{mIU} / \mathrm{l}$. Serum lipid levels are influenced by thyroid status and there is evidence pointing to a link between SCH and an unfavorable lipid profile. Despite some conflicting data, most studies suggest that levothyroxine treatment may exert a beneficial effect on the lipid profile in SCH regarding mainly total cholesterol and low-density lipoproteincholesterol. Moreover, it appears that treatment may also improve some other markers associated with cardiovascular (CV) disease such as carotid intima media thickness (cIMT) indices of endothelial function and other predictors of vascular risk. The complex interaction between SCH and predictors of vascular disease may explain the variability of the results obtained from studies that assessed vascular events or even changes in some biochemical, functional or structural variables associated with an increased risk of vascular events. Further investigation is warranted by means of intervention studies to assess the clinical significance of levothyroxine treatment in $\mathrm{SCH}$ regarding $\mathrm{CV}$ risk.
\end{abstract}

Key words: Cardiovascular disease, Carotid, Lipids, Subclinical hypothyroidism

\section{INTRODUCTION}

Subclinical hypothyroidism (SCH) is defined as elevated serum thyroid-stimulating hormone (TSH) levels in the presence of circulating free thyroxine

\section{Address for correspondence:}

Dimitri P. Mikhailidis MD, FFPM, FRCP, FRCPath, Academic Head of Department, Department of Clinical Biochemistry, Royal Free Hospital campus, University College London Medical School, University College London (UCL), London NW3 2QG, UK, Tel.: +442078302258,

Fax: +442078302235, E-mail: mikhailidis@aol.com

Received 17-03-2013, Accepted 20-10-2013
(FT4) and triiodothyronine (T3) levels within the reference range. ${ }^{1}$ This is a relatively common condition with a prevalence ranging from 4 to $15 \%$ in the general population and up to $20 \%$ among females aged $>60$ years..$^{2-5}$

The need for replacement therapy with levothyroxine in $\mathrm{SCH}$ remains a subject of debate. Currently, routine treatment of $\mathrm{SCH}$ is not recommended. ${ }^{6}$ Replacement treatment with levothyroxine is justified for individuals with TSH levels $>10 \mathrm{mIU} /{ }^{6}{ }^{6}$

There is a close association between thyroid func- 
tion and the lipid profile with overt hypothyroidism being strongly related to dyslipidemia. ${ }^{7,8}$ Because of diminished numbers of low-density lipoprotein (LDL) receptors in the liver, the fractional excretion of LDLcholesterol (LDL-C) is reduced in hypothyroidism. Moreover, cholesterol oxidation is enhanced in hypothyroidism. ${ }^{9}$ It appears that total cholesterol (TC) and LDL-C concentrations are positively correlated with TSH in the general population independent of thyroid status. ${ }^{10}$ Furthermore, there is a well established association between dyslipidemia and increased cardiovascular (CV) risk. ${ }^{11}$ Therefore, it is of interest to assess the relationship between $\mathrm{SCH}$ and an adverse lipid profile and to establish whether levothyroxine treatment can reduce any associated $\mathrm{CV}$ risk.

\section{METHODS}

We searched PubMed up to 10 January 2013 using combinations of the following keywords: subclinical hypothyroidism, dyslipidemia, hypercholesterolemia, lipids, cardiovascular disease, atherosclerosis, endothelial dysfunction, treatment, levothyroxine. Randomized controlled trials, original papers and review articles were included. References of these articles were scrutinized for additional relevant articles.

\section{RESULTS}

\section{SCH and Dyslipidemia}

Epidemiological population-based studies suggest a link between $\mathrm{SCH}$ and an unfavorable lipid profile. In the Colorado Study, 25,852 individuals with $\mathrm{SCH}$ had significantly higher TC and LDL-C concentrations compared with euthyroid subjects $(\mathrm{p}<0.001) .{ }^{2} \mathrm{TSH}$ and lipid levels were associated in a dose-dependent manner [ $\mathrm{p}$ for trend $<0.001$ for TC and LDL-C and 0.02 for triglycerides (TG)]. Consistently, in another community-based study $(\mathrm{n}=2108)$, TC and LDL-C levels were higher among individuals with $\mathrm{SCH}$ than euthyroid participants (although the comparison for $\mathrm{TC}$ was borderline non-significant after adjustment for age and sex; $p=0.06){ }^{10}$

A study based on an Indian population $(n=5343)$ included both adults and children/adolescents. ${ }^{12}$ The prevalence of $\mathrm{SCH}$ was $13.5 \%$. When $\mathrm{SCH}$ subjects were divided into 2 groups using a TSH cut-off point of $10 \mathrm{mU} / \mathrm{l}$, those with a TSH level below this value showed no lipid abnormalities. On the other hand, patients with TSH concentrations $>10 \mathrm{mU} / 1$ had significantly greater levels of TC and LDL-C (p $<0.0001$ for both) as well as lower HDL-C ( $\mathrm{p}=$ $0.001)$ compared with controls. TSH positively correlated with TC $(\mathrm{r}=0.037 ; \mathrm{p}=0.007)$ and LDL-C $(\mathrm{r}=0.028 ; \mathrm{p}=0.037)$ but negatively with HDL-C $(\mathrm{r}$ $=0.031 ; \mathrm{p}=0.018)$ in the whole study population. In another study including elderly participants $(\mathrm{n}=$ 2799), SCH ( $=62$ ) was associated with higher TC levels compared with the euthyroid state only among black women ( $p$ <.001). ${ }^{13}$ Nevertheless, higher TSH levels were associated with higher TC concentrations in the entire cohort.

In line with the above, findings from several smaller studies indicate an association between dyslipidemia and SCH. ${ }^{14-18}$ Overall, TC and LDL-C are particularly affected. It appears that increased TSH levels are associated with dyslipidemia without a cut-off threshold for this relation, with dyslipidemia being more prevalent with increasing degree of thyroid hypofunction. ${ }^{19}$ It has also been suggested that $\mathrm{SCH}$ is associated with an intermediately adverse lipid profile between that of euthyroid individuals and that of patients with overt hypothyroidism. ${ }^{20}$ Other factors such as insulin resistance and smoking may augment the adverse effect of TSH on lipids. ${ }^{21}$ Moreover, serum lipids may be significantly affected by thyroid function even in euthyroid subjects. In individuals with no history of thyroid abnormalities or relevant treatment, TSH within the normal range positively correlated with TC $(p=0.001)$, TG $(p=0.001)$ and LDL-C $(p=$ 0.003 ) even after adjustment for confounding factors (e.g. age, sex and obesity). ${ }^{22}$ TSH concentrations also linearly correlated with TC, non-HDL-C and TG levels $(\beta=0.173,0.181$ and 0.103 , respectively; $p<0.01)$ in euthyroid non-smokers with CHD $(n=406) .{ }^{23}$

It should be noted that some studies have reported increased levels of lipoprotein (a) [Lp(a)] associated with $\mathrm{SCH},{ }^{14,15,24}$ but others did not confirm this finding. ${ }^{14,25} \mathrm{Lp}(\mathrm{a})$ has been considered as an independent risk factor for cardiovascular events. ${ }^{26}$

Nevertheless, other studies have yielded conflicting findings, indicating either no difference in lipid profile between $\mathrm{SCH}$ and euthyroid status ${ }^{27-30}$ 
or an association of $\mathrm{SCH}$ with lipid variables other than TC and LDL-C. ${ }^{4,31,32}$ In National Health and Nutrition Examination Survey III (NHANES III), a large population-based study, subjects with $\mathrm{SCH}$ $(\mathrm{n}=215)$ showed no significant differences in lipid parameters compared with euthyroid individuals ( $\mathrm{n}$ $=8013$ ) when adjusted for age, race, sex and the use of lipid-lowering agents. ${ }^{27}$ Neither logistic regression analysis (distinguishing between normal or abnormal lipid levels) nor linear regression analysis (testing a continuous relationship between lipid and TSH levels) demonstrated any significant association. ${ }^{27}$

Consistently, among 1212 individuals, those with $\mathrm{SCH}(\mathrm{n}=249)$ did not differ from euthyroid controls $(\mathrm{n}=963)$ regarding their lipid profile [except for TG levels which were significantly higher $(p<0.001)] .{ }^{4}$ It is of interest that postprandial lipemia was the only adverse feature of lipid profile associated with $\mathrm{SCH}$ as reported in a small study. ${ }^{31}$ Postprandial lipemia, i.e. increased non-fasting TG concentration, is considered a CV risk factor. ${ }^{33,34}$ In this study ${ }^{31} \mathrm{TC}$, LDL-C, verylow-density lipoprotein-cholesterol (VLDL-C) and TG levels of patients with overt hypothyroidism $(\mathrm{OH})$ $(\mathrm{n}=25)$ or SCH $(\mathrm{n}=27)$ were similar to controls; however, mean TG concentrations at postprandial $8^{\text {th }}$ hour were significantly greater in patients with $\mathrm{OH}$ and $\mathrm{SCH}$ compared with their euthyroid counterparts ( $p=0.017$ and $p=0.049$, respectively). TSH concentrations positively correlated with postprandial $8^{\text {th }}$ hour concentrations of TG $(\mathrm{r}=0.320 ; \mathrm{p}=$ $0.008)$, TC $(r=0.247 ; p=0.03)$ and VLDL-C $(r=$ $0.278 ; p=0.022)$. We should note that patients did not differ from controls with regard to measures of glucose tolerance that could confound findings of postprandial lipemia.

In another study, middle-aged women with $\mathrm{SCH}$ $(\mathrm{n}=95)$ did not differ from controls $(\mathrm{n}=65)$ with regard to TC and LDL-C concentrations but had significantly higher TG and lower HDL-C levels. In addition, higher values of TSH $(>10 \mathrm{mIU} / \mathrm{l})$ were associated with an atherogenic pattern B of LDL-C subfractions (i.e. small dense LDL particles) compared with lower TSH $(<5 \mathrm{mIU} / \mathrm{l})$. Small dense LDL particles are associated with enhanced atherogenicity and, therefore, increased $\mathrm{CV}$ risk. ${ }^{35,36} \mathrm{~A}$ link between small dense LDL and $\mathrm{OH}$ has been previously suggested. ${ }^{37}$ In this study, ${ }^{32} \mathrm{~B}$ LDL profile was more prevalent among patients with TSH $>10 \mathrm{mIU} / \mathrm{l}(30 \%)$ than in those with TSH, ranging from 5 to $10 \mathrm{mIU} / \mathrm{l}$ or $<5$ $\mathrm{mIU} / \mathrm{l}$ (13.6 and 5.9\%, respectively).

There is also some evidence implying a link between $\mathrm{SCH}$ and the presence of metabolic syndrome (MetS). ${ }^{22,38,39}$ However, further studies failed to confirm such an association..$^{40-42}$ Finally, regarding the importance of non-traditional CV risk factors (such as thrombotic markers and arterial stiffness), these remain to be elucidated since data are not conclusive. $^{43-53}$

\section{Effect of Levothyroxine Treatment}

Several studies assessed the effect of levothyroxine replacement treatment on the lipid profile in patients with $\mathrm{SCH}$.

In a systematic review data from 13 studies, 247 subjects were analyzed regarding lipid changes after thyroxine therapy for $\mathrm{SCH} .{ }^{54}$ Among populations studied there were individuals with untreated mild thyroid failure (consistent with the definition of SCH) as well as patients with a history of overt hypothyroidism receiving suboptimal levothyroxine therapy, insufficient to normalize TSH levels. Treatment duration was at least 12 weeks. Information on TC levels was reported in all 13 studies, while data on TG, LDL-C and HDL-C levels were provided in 12, 10 and 9 studies, respectively. Overall, small but significant reductions were reported in TC $[7.9 \mathrm{mg} / \mathrm{dL}$; 95\% confidence interval (CI), 3.3 to 13] and LDL-C $(10 \mathrm{mg} / \mathrm{dL} ; 95 \%$ CI, 4.0 to 16$)$ levels. Considerable heterogeneity was found among studies. Nevertheless, use of a random effects model yielded similar results. Among studies, two showed no significant change in TC and LDL-C. There was a positive correlation between the change in TC levels and its initial concentration $(\mathrm{r}=0.55)$. Moreover, the change in TC levels was greater for patients with suboptimally treated overt hypothyroidism after normalization of TSH levels than for those with untreated SCH ( $p$ $<0.05)$. Changes in TG and HDL-C concentrations were not significant. Heterogeneity among studies was accounted for in analyses. ${ }^{54}$

Consistently, a former review had demonstrated a decline of $0.4 \mathrm{mmol} / \mathrm{l}(15.5 \mathrm{mg} / \mathrm{dl})(95 \% \mathrm{Cl} 0.2-0.6$ $\mathrm{mmol} / \mathrm{l})$ in TC levels after normalization of TSH 
levels following levothyroxine therapy in $\mathrm{SCH} .{ }^{55}$ This reduction was not correlated with pre-treatment TC concentrations. Meanwhile, the respective reduction observed in patients with overt hypothyroidism was greater and positively associated with TC levels at baseline.

In a randomized double-blind placebo-controlled trial, 12-month levothyroxine treatment with 31 patients (achieving a period of euthyroidism of at least 4 months) resulted in significant reductions in TC and LDL-C levels $(3.8 \%$; $=0.015$ and $8.2 \%$; $=$ 0.004 , respectively, compared with placebo $(\mathrm{n}=32) .{ }^{56}$ Treatment with levothyroxine also achieved a slight but significant decrement in apolipoprotein (apo) B-100 concentrations. Nevertheless, comparing the mean treatment effect of levothyroxine $v s$ placebo did not yield a significant difference. Replacement therapy achieved greater lipid reductions in patients with higher baseline TSH (12 mIU/l) and TC, LDL-C concentrations. Consistently, 1 year after restoration of euthyroid status by levothyroxine replacement therapy, 11 patients had significantly reduced TC and LDL-C levels compared with those on placebo $(\mathrm{n}=15) \cdot{ }^{20}$ In line with the above, in another trial ( $\mathrm{n}$ $=100$ ) with a crossover design (patients changed to the opposite treatment arm i.e. thyroxine $v s$ placebo after 12 weeks), TC and LDL-C concentrations were reduced by $5.5 \%(\mathrm{p}<0.0001)$ and $7.3 \%(\mathrm{p}=0.05)$, respectively. ${ }^{57}$

A lipid evaluation 6 months after TSH normalization with levothyroxine treatment in patients with $\mathrm{SCH}$ $(\mathrm{n}=49)$ showed a decline in TC and LDL-C values ( 8 and $10.2 \%$, respectively; $p=0.003$ for both). ${ }^{14}$ The absolute lipid reductions positively correlated with the baseline TC and LDL-C concentrations ( $\mathrm{r}$ $=0.43, \mathrm{p}=0.05$ and $\mathrm{r}=0.54, \mathrm{p}=0.01$, respectively). Moreover, there was a positive association between TC and LDL-C decrements and baseline TSH levels ( $\mathrm{r}$ $=0.54, p=0.01$ and $r=0.57, p=0.005$, respectively) as well as with the reduction in serum TSH $(\mathrm{r}=0.59$, $\mathrm{p}=0.002$ and $\mathrm{r}=0.60, \mathrm{p}=0.002$, respectively). ${ }^{14}$ Another 6-month intervention study also showed that TC and LDL-C levels were reduced by $10.5 \%$ $(\mathrm{p}<0.01)$ and $14.7 \%(\mathrm{p}<0.001)$, respectively, after levothyroxine treatment. ${ }^{58}$

Moreover, after 3 months of stable euthyroid status subsequent to levothyroxine treatment, elderly patients with $\mathrm{SCH}(\mathrm{n}=25)$ experienced significant improvement in most lipid parameters (except for HDL-C) ${ }^{59}$ Elderly patients (65 years and older) with $\mathrm{OH}(\mathrm{n}=31)$ included in the same study showed similar changes in lipid profile with an additional improvement in HDL-C. ${ }^{59}$

Accordingly, 6-month treatment with levothyroxine and normalization of TSH ameliorated the adverse lipid profile of elderly women with $\mathrm{SCH}(\mathrm{n}$ $=17) .{ }^{60}$ Concentrations of TC $(p=0.017)$, LDL-C $(\mathrm{p}=0.014)$, TC/HDL-C $(\mathrm{p}=0.05)$, TC/LDL-C $(\mathrm{p}$ $=0.03), \mathrm{Lp}(\mathrm{a})(\mathrm{p}=0.0005)$ and apoB $(\mathrm{p}=0.013)$ were significantly reduced; however, apoAI levels were also decreased and HDL-C was reduced but not significantly. In another study $(\mathrm{n}=42)$, levothyroxine treatment conferred small but significant reductions in TC ( $p<0.05)$, LDL-C ( $p<0.01)$ and apoB $(\mathrm{p}<0.01)$ levels, but failed to improve a series of emerging cardiovascular risk markers such as homocysteine, C-reactive protein (CRP) and Lp(a) ${ }^{61}$ Also, long-term (18 months) levothyroxine treatment significantly reduced TC $(\mathrm{p}=0.023)$, LDL-C $(\mathrm{p}=0.018)$ and $\operatorname{Lp}(\alpha)(p=0.005)$ levels in a female population with $\mathrm{SCH}$, reaching values similar to healthy controls. ${ }^{24}$

Favorable lipid effects of levothyroxine replacement therapy in $\mathrm{SCH}$ patients regarding especially TC and LDL-C levels have also been shown in several small studies. . $^{16,62,63}$

Nevertheless, some other studies have yielded variable results inadequate to support a clear-cut lipid benefit of levothyroxine replacement treatment in $\mathrm{SCH}$. In an intervention trial, part of the $5^{\text {th }}$ Tromso study, no significant lipid reductions were noted in $\mathrm{SCH}$ treated with levothyroxine $(\mathrm{n}=32)$ compared with placebo $(\mathrm{n}=32) \cdot{ }^{64}$ However, a subanalysis of data only for those with post-treatment TSH levels of 0.2-1.99 mIU/l (reference range 0.5-3.5 mIU/1) yielded significant reductions in TC $(5 \%$; $p<0.05)$, LDL-C $(9 \%)$ and apoB (8\%; $\mathrm{p}<0.01$ for both). Moreover, there are data showing significant TC and LDL-C reductions after levothyroxine replacement therapy only among $\mathrm{SCH}$ patients with pre-treatment TC levels exceeding $240 \mathrm{mg} / \mathrm{dl}^{15}$ or TSH $>10 \mu \mathrm{U} / \mathrm{ml}^{15,17}$ Other results showed that levothyroxine treatment significantly reduced $\mathrm{TC}$, non-HDL-C, remnant-like 
particle (RLP)-C and apoB levels in SCH patients but not LDL-C, although normalization of serum TSH had been achieved. ${ }^{65,66}$

On the other hand, there are also several studies demonstrating no significant benefit in lipid profile in patients with $\mathrm{SCH}$ receiving levothyroxine treatment. ${ }^{47,67-71}$

Overall, it appears that the beneficial effect-if any - of levothyroxine treatment on lipid profile in $\mathrm{SCH}$ mainly concerns TC and LDL-C levels. TG concentrations are not significantly affected. As far as HDL-C is concerned, most studies demonstrate no significant effect of levothyroxine substitution on HDL-C concentrations in SCH. ${ }^{16,18,20,24,47,60-63,65-67,69,70}$ Nevertheless, there is limited evidence suggesting either a lowering ${ }^{15,17,59,72}$ or an increasing effect. ${ }^{71,73}$

\section{SCH and CV Disease}

A link between hypothyroidism and atherosclerosis was first suspected more than a century ago. ${ }^{74}$ The first data came from autopsy studies which described increased atherosclerotic burden in hypothyroid patients. Since then, several studies have evaluated $\mathrm{CV}$ outcomes as well as subclinical markers of atherosclerosis yielding variable results.

Evidence regarding the association of $\mathrm{SCH}$ and the risk of $\mathrm{CV}$ disease appear conflicting in epidemiological studies. The Cardiovascular Health Study, a community-based study $(\mathrm{n}=3233)$, showed no increased incidence of fatal or non-fatal CV events in individuals with $\mathrm{SCH}(\mathrm{n}=496) \cdot{ }^{75}$ Another population study $(\mathrm{n}=2730)$ showed an increased risk for heart failure but not for any atherosclerotic events and mortality associated with $\mathrm{SCH}(\mathrm{n}=338) \cdot{ }^{76}$ Further data have also failed to conclusively demonstrate an increased risk for CVD in older patients and postmenopausal women with SCH. ${ }^{77,78}$

In contrast, a meta-analysis of 15 studies showed an increased prevalence and incidence of coronary heart disease (CHD) in patients with $\mathrm{SCH}$ compared with euthyroid individuals; nevertheless, this was true only among subjects younger than 65 years (OR 1.57, 95\% CI $1.19-2.06 ; \mathrm{p}=0.001$ and OR $1.68,95 \% \mathrm{CI}$ $1.27-2.23 ; p=0.001$, respectively). ${ }^{79}$ Moreover, these younger individuals with $\mathrm{SCH}$ had an increased risk for CV death (OR 1.3795\% CI $1.04-1.79 ; \mathrm{p}=0.02$ ) compared with those with normal thyroid function. This is in line with other findings demonstrating $\mathrm{SCH}$ as an independent predictor for $\mathrm{CV}$ disease in younger men $\left(<50\right.$ years of age).${ }^{4}$ Consistently, another study $(\mathrm{n}=2856)$ demonstrated an increased risk for CHD in individuals with $\mathrm{SCH}(\mathrm{n}=292)$ compared with euthyroid subjects (OR 2.6; 95\% CI, 1.2 - 5.6; $\mathrm{p}=$ 0.02 after adjustment for age and sex). ${ }^{28}$ This association lost significance for women in a separate gender analysis. Significance of these relations in the entire cohort and men was preserved after adjustment for other CV risk factors (e.g. smoking, lipid levels and blood pressure). ${ }^{28}$ In another community-based study, CHD was significantly more prevalent among patients with SCH $(n=119)$ than euthyroid individuals ( $\mathrm{n}$ = 1906) even after adjustment for conventional CV risk factors (OR 2.2, 95\% CI $1.2-4.0 ; \mathrm{p}=0.01) .{ }^{80}$ Longitudinal data from the same study for subjects without CHD at baseline showed an increased hazard ratio (HR) for coronary events in those with $\mathrm{SCH}$ (n $=101 ; \mathrm{HR} 1.7,95 \%$ CI $1.2-2.4 ; \mathrm{p}<0.01)$ compared with euthyroid persons $(\mathrm{n}=1752){ }^{80}$

Other non-traditional $\mathrm{CV}$ factors such as plasma viscosity, endothelial dysfunction, CRP and mean platelet volume (MPV) may also be affected in SCH..$^{53,81-84}$ Whether a "dysfunctional" $\mathrm{HDL}^{85}$ plays a role in any potential link between $\mathrm{SCH}$ and $\mathrm{CV}$ risk remains to be established.

\section{Effect of Levothyroxine Treatment on Other Cardiovascular Risk Markers}

In addition to the relationship between $\mathrm{SCH}$ and an unfavorable lipid profile, other markers associated with $\mathrm{CV}$ risk can be adversely affected in $\mathrm{SCH}$. Levothyroxine administration in $\mathrm{SCH}$ patients may have an additional ameliorating effect on such markers, even -in some instances - in the absence of a concomitant effect on lipid profile.

Overt hypothyroidism is associated with surrogate markers of atherosclerosis such as carotid intima media thickness (cIMT). ${ }^{86,87}$ Increased values of cIMT have been reported in patients with SCH compared with euthyroid individuals. ${ }^{62,86}$ This relation may be mediated by classical cardiovascular risk factors such as hypertension, hyperlipidemia commonly associated with $\mathrm{SCH}$ as well as high TSH levels per se. ${ }^{88}$ There is some evidence suggesting a beneficial effect of levothy- 
roxine replacement therapy on cIMT in subjects with $\mathrm{SCH}$. In particular at 6 months of stable euthyroidism achieved by levothyroxine treatment, cIMT displayed a mean reduction of $0.09 \mathrm{~mm}(95 \% \mathrm{CI} 0.06-0.11)$ or $10 \% .{ }^{62}$ Mean cIMT values positively correlated with TSH levels $(r=0.51, p=0.0008)$. There was also a significant positive association between the absolute reduction in mean cIMT and that in serum TC and TSH concentrations $(\mathrm{r}=0.35, \mathrm{p}=0.02$ and $\mathrm{r}=0.61$, $\mathrm{p}=0.0001$, respectively). ${ }^{62}$ Consistently, following 1 year of euthyroidism with levothyroxine therapy, cIMT was significantly decreased by $0.07 \pm 0.06 \mathrm{~mm}$ $(\mathrm{p}=0.021)$ in patients with SCH $(\mathrm{n}=20) .{ }^{16}$ Similarly, treatment with levothyroxine and normalization of thyroid function conferred a decrease of $0.08 \mathrm{~mm}$ in cIMT in another study $(\mathrm{n}=40) .{ }^{86} \mathrm{~A}$ small but significant decrease in cIMT (mean 0.01, $\mathrm{p}=0.008$ ) has also been noted after a shorter period ( 3 months) of euthyroidism achieved by levothyroxine substitution in $\mathrm{SCH}$ patients $(\mathrm{n}=38) .{ }^{72}$ This reduction was not related to concomitant change in other variables such as lipids.

Consistently, a similar mean decrement in cIMT $(13 \% ; 0.01 \mathrm{~mm}, \mathrm{p}=0.046)$ was achieved after 18 months of levothyroxine therapy in a female population with $\mathrm{SCH}(\mathrm{n}=20) .{ }^{24} \mathrm{In}$ addition, blood pressure (BP) was improved ( $\mathrm{p}=0.001$ for systolic BP and $\mathrm{p}$ $=0.005$ for diastolic BP) and renal function indices (i.e. serum creatinine, cystatin $\mathrm{C}$ and estimated glomerular filtration rate (eGFR) $(\mathrm{p}=0.001$ for all $)$ were enhanced following levothyroxine replacement therapy. The mean common carotid artery diameter, baseline brachial artery diameter as well as glyceryl trinitrite-mediated diameter all significantly increased $(\mathrm{p}<0.05)$ after levothyroxine treatment. However in this study the period of stable euthyroidism with treatment is not reported. ${ }^{24}$

One study compared the effect of statin therapy to that of levothyroxine replacement in $\mathrm{SCH}$ patients. ${ }^{68}$ Patients allocated to levothyroxine $(n=20)$ exhibited a decrement in mean cIMT comparable to that conferred by simvastatin treatment $(\mathrm{n}=$ 20). Levothyroxine replacement therapy exerted no beneficial effect on lipid profile in contrast to statin therapy. Therefore, the cIMT reduction associated with levothyroxine replacement cannot be attributed to improved lipid parameters. ${ }^{68}$
On the other hand, 1-year treatment with levothyroxine conferred no improvement in cIMT in women with $\mathrm{SCH}(\mathrm{n}=32),{ }^{67}$ but decelerated the deterioration in brachial artery flow-mediated dilatation (FMD), an effect also noted in the study group receiving no treatment. Moreover, there is additional evidence suggesting a beneficial effect of levothyroxine treatment on endothelial function in SCH. Twelve-week levothyroxine replacement improved brachial artery FMD in patients with SCH $(\mathrm{n}=100) v s$ placebo (5.9 vs $4.2 \% ; \mathrm{p}=0.001) .{ }^{57}$ Several other markers of endothelial function (e.g. forearm blood flow response to intrabrachial acetylcholine, response to sodium nitroprusside and minimal forearm vascular resistance) also appear to improve by levothyroxine administration in subjects with SCH $(\mathrm{n}=14) .{ }^{89}$

Serum asymmetrical dimethyl arginine (ADMA), an endogenous inhibitor of nitric oxide synthase (NOS), as well as CRP and L-arginine levels can be increased in $\mathrm{SCH}$, while nitric oxide production is decreased compared with controls. ${ }^{18}$ These markers were significantly ( $p<0.05$ for all) improved after 1 month of stable euthyroidism following levothyroxine treatment, although lipid profile was not affected. Unexpectedly, $\mathrm{SCH}$ patients in this study were found to have lower small dense LDL levels than controls. These were increased by levothyroxine substitution, while TC and LDL-C concentrations were not affected. ${ }^{18}$

A novel marker of CV risk, low circulating endothelial progenitor cells (EPC), has also been related to $\mathrm{SCH}$ independently of lipids and other variables (n $=20) \cdot{ }^{90} \mathrm{EPC}$ number increased after levothyroxine treatment, whereas no significant amelioration of lipid profile (except for a small increase in HDL-C) was noticed.

Several studies have examined the importance of other parameters associated with the atherosclerotic process (such as inflammatory and thrombotic markers or endothelium-related molecules) in $\mathrm{SCH}$ and the effect of levothyroxine replacement on them. However, no significant benefit has been demonstrated..$^{24,47,61,72}$

There is considerable evidence suggesting that levothyroxine replacement therapy in $\mathrm{SCH}$ may improve the lipid profile. This ameliorating effect regards mainly TC and LDL-C. Nevertheless, this was not confirmed in all studies. 
The studies presented in this overview have several limitations. First, there are discrepancies among the populations studied in terms of their characteristics (e.g. age, gender, body mass index, comorbidities and SCH etiology). Some studies included only younger individuals, ${ }^{14,62}$ others recruited only elderly people, ${ }^{59,60}$ while most of them had no age cut-offs. Some studies included only women. ${ }^{24,67,71}$ The etiology of SCH was mentioned in some studies ${ }^{17,62,65,66}$ but not in others, ${ }^{15,59,71,72}$ while percentages of certain $\mathrm{SCH}$ causes differed among populations. Furthermore, conditions which affect lipid metabolism were not taken into consideration in either patient selection or data analysis in some studies. ${ }^{17,59,69}$ Diabetic individuals were excluded from most studies but insulin resistance, an important determinant of lipid metabolism, was not accounted for. In addition, different treatment time periods and levothyroxine dose were used. In many cases, it was not reported whether ${ }^{17,63}$ or for how long ${ }^{24,65,66}$ euthyroidism had been restored before post-treatment measurements.

\section{Other less well established links between SCH and vascular risk}

There is some evidence implying an increased CV risk in $\mathrm{SCH}$ but a clear association between $\mathrm{SCH}$ and $\mathrm{CV}$ disease has yet to be firmly established. SCHrelated autoimmunity has been suggested as being implicated in the development of atherosclerosis in these patients; ${ }^{91,92}$ however, further studies did not support this. ${ }^{93,94}$

An increased MPV has been reported in $\mathrm{SCH} .{ }^{53}$ This was reversed on achieving euthyroid status. In addition, MPV has been linked to low-grade inflammation and thrombosis risk. ${ }^{95}$ In this context, in an adult Taiwanese population SCH was associated with elevated high sensitivity CRP (hsCRP) quartiles, suggesting a link with inflammatory status. ${ }^{96}$

Although there is no evidence that antioxidants reduce vascular risk, it is of interest that severity of hypothyroidism appears to contribute to the antioxidant deficiency and oxidant stress..$^{97,98}$

$\mathrm{SCH}$ is related to non-alcoholic fatty liver disease (NAFLD) in a dose-dependent manner independently of metabolic risk factors. ${ }^{99}$ Moreover, NAFLD and abnormal liver tests are associated with an increased risk of vascular events. ${ }^{99-102}$ The link between NAFLD and $\mathrm{SCH}$ may, at least in part, be due to decreased hepatic very-low-density lipoprotein (VLDL)-TG secretion that occurs in hypothyroidism. ${ }^{103}$ The association between $\mathrm{SCH}$ and MetS may also be relevant since NAFLD is the hepatic expression of MetS. ${ }^{104,105}$ It is also of interest that epicardial fat, another form of abnormal fat accumulation, is associated with $\mathrm{SCH}$, NAFLD, MetS and vascular risk. ${ }^{106,107}$

There is more to BP assessment than just occasional office-based measurements. Therefore, it is of interest that raised TSH levels have been linked to decreased nocturnal BP-dipping. ${ }^{108}$ Similarly, a meta-analysis $(\mathrm{SCH}=$ about 1783 patients; euthyroid about 15,540 patients depending on which subgroups were analyzed) reported that $\mathrm{SCH}$ was associated with both raised systolic and diastolic BP. ${ }^{109}$

Chronic kidney disease (CKD) is now recognized as another condition associated with a high risk of vascular events. ${ }^{110,111}$ Therefore, it is of interest that thyroid hormone therapy preserved renal function and was also an independent predictor of renal outcome in $\mathrm{CKD}$ patients with $\mathrm{SCH} .{ }^{112}$

The relationship between $\mathrm{SCH}$ and vascular risk possibly extends to treatment since thyroid status increases the risk of myositis in patients taking statins. ${ }^{113}$

\section{CONCLUSIONS}

A possible role for levothyroxine replacement therapy in $\mathrm{SCH}$-associated dyslipidemia could be reasonable in an effort to eventually reduce $\mathrm{CV}$ risk. Recent findings have demonstrated an ameliorating effect of levothyroxine treatment on markers of subclinical atherosclerosis, such as cIMT, indices of endothelial dysfunction and several other predictors of vascular risk. However, so far there are insufficient data to support an undisputed benefit of levothyroxine treatment in $\mathrm{SCH}$ in terms of $\mathrm{CV}$ disease prevention. Therefore, further investigation is warranted. There is a need for intervention studies to assess the effect of levothyroxine treatment on clinical outcomes (i.e. CV events) rather than just laboratory measurements in $\mathrm{SCH}$. In view of all the numerous documented links between $\mathrm{SCH}$ and predictors of vascular risk (see above), such studies will need to include very large numbers of patients to enable effective matching as well as multivariate analyses. It may, however, be 
very difficult to fund such trials. Furthermore, the complex interaction between $\mathrm{SCH}$ and predictors of vascular disease may also explain the variability of the results obtained from studies that assessed vascular events or even changes in some biochemical, functional or structural variables associated with an increased risk of vascular events. Finally, with a relative risk of vascular death (after correction for several vascular risk factors) of 1.68 (95\% CI: 1.02 - 2.76) in patients with $\mathrm{SCH}$ (compared with those who were euthyroid) over a 10 -year period, ${ }^{114}$ we need to consider whether $\mathrm{SCH}$ should be classed as a CHD equivalent when this condition occurs in the presence of other vascular risk factors.

\section{Declaration of interest}

Dimitri P. Mikhailidis has given talks, attended conferences and participated in trials and advisory boards sponsored by MSD, Genzyme and Abbott.

\section{REFERENCES}

1. Garber JR, Cobin RH, Gharib H, et al, 2012 Clinical practice guidelines for hypothyroidism in adults: cosponsored by the American Association of Clinical Endocrinologists and the American Thyroid Association. Endocr Pract 18: 988-1028.

2. Canaris GJ, Manowitz NR, Mayor G, Ridgway EC 2000 The Colorado Thyroid Disease Prevalence Study. Arch Intern Med 160: 526-534.

3. Hollowell JG, Staehling NW, Flanders WD, et al, 2002 Serum TSH, T(4), and thyroid antibodies in the United States population (1988 to 1994): National Health and Nutrition Examination Survey (NHANES III). J Clin Endocrinol Metab 87: 489-499.

4. Kvetny J, Heldgaard PE, Bladbjerg EM, Gram J, 2004 Subclinical hypothyroidism is associated with a lowgrade inflammation, increased triglyceride levels and predicts cardiovascular disease in males below 50 years. Clin Endocrinol (Oxf) 61: 232-238.

5. Sawin CT, Castelli WP, Hershman JM, McNamara P, Bacharach P, 1985 The aging thyroid. Thyroid deficiency in the Framingham Study. Arch Intern Med 145: 13861388.

6. Surks MI, Ortiz E, Daniels GH, et al, 2004 Subclinical thyroid disease: scientific review and guidelines for diagnosis and management. JAMA 291: 228-238.

7. Neves C, Alves M, Medina JL, Delgado JL, 2008 Thyroid diseases, dyslipidemia and cardiovascular pathology. Rev Port Cardiol 27: 1211-1236.

8. Pucci E, Chiovato L, Pinchera A, 2000 Thyroid and lipid metabolism. Int J Obes Relat Metab Disord 24:
Suppl 2: 109-112.

9. Duntas LH, 2002 Thyroid disease and lipids. Thyroid 12: 287-293.

10. Walsh JP, Bremner AP, Bulsara MK, et al, 2005 Thyroid dysfunction and serum lipids: a community-based study. Clin Endocrinol (Oxf) 63: 670-675.

11. 1994 National Cholesterol Education Program. Second Report of the Expert Panel on Detection, Evaluation, and Treatment of High Blood Cholesterol in Adults (Adult Treatment Panel II). Circulation 89: 1333-1445.

12. Marwaha RK, Tandon N, Garg MK, et al, 2011 Dyslipidemia in subclinical hypothyroidism in an Indian population. Clin Biochem 44: 1214-1217.

13. Kanaya AM, Harris F, Volpato S, et al, 2002 Association between thyroid dysfunction and total cholesterol level in an older biracial population: the health, aging and body composition study. Arch Intern Med 162: 773-779.

14. Caraccio N, Ferrannini E, Monzani F, 2002 Lipoprotein profile in subclinical hypothyroidism: response to levothyroxine replacement, a randomized placebo-controlled study. J Clin Endocrinol Metab 87: 1533-1538.

15. Efstathiadou Z, Bitsis S, Milionis HJ, et al, 2001 Lipid profile in subclinical hypothyroidism: is L-thyroxine substitution beneficial? Eur J Endocrinol 145: 705-710.

16. Kim SK, Kim SH, Park KS, Park SW, Cho YW, 2009 Regression of the increased common carotid arteryintima media thickness in subclinical hypothyroidism after thyroid hormone replacement. Endocr J 56: 753758.

17. Miura S, Iitaka M, Yoshimura H, et al, 1994 Disturbed lipid metabolism in patients with subclinical hypothyroidism: effect of L-thyroxine therapy. Intern Med 33: 413-417.

18. Ozcan O, Cakir E, Yaman H, et al, 2005 The effects of thyroxine replacement on the levels of serum asymmetric dimethylarginine (ADMA) and other biochemical cardiovascular risk markers in patients with subclinical hypothyroidism. Clin Endocrinol (Oxf) 63: 203-206.

19. Duntas LH, Brenta G, 2013 The effect of thyroid disorders on lipid levels and metabolism. Med Clin North Am 96: 269-281.

20. Teixeira Pde F, Reuters VS, Ferreira MM, et al, 2008 Lipid profile in different degrees of hypothyroidism and effects of levothyroxine replacement in mild thyroid failure. Transl Res 151: 224-231.

21. Pearce EN, 2012 Update in lipid alterations in subclinical hypothyroidism. J Clin Endocrinol Metab 97: 326-333.

22. Lee YK, Kim JE, Oh HJ, et al, 2011 Serum TSH level in healthy Koreans and the association of TSH with serum lipid concentration and metabolic syndrome. Korean J Intern Med 26: 432-439.

23. Wanjia X, Chenggang W, Aihong W, et al, 2012 A high normal TSH level is associated with an atherogenic lipid profile in euthyroid non-smokers with newly diagnosed asymptomatic coronary heart disease. Lipids Health Dis 
11: 44 .

24. Adrees M, Gibney J, El-Saeity N, Boran G 2009 Effects of 18 months of L-T4 replacement in women with subclinical hypothyroidism. Clin Endocrinol (Oxf) 71: 298-303.

25. Tzotzas T, Krassas GE, Konstantinidis T, Bougoulia M, 2000 Changes in lipoprotein(a) levels in overt and subclinical hypothyroidism before and during treatment. Thyroid 10: 803-808.

26. Nordestgaard BG, Chapman MJ, Ray K, et al, Lipoprotein(a) as a cardiovascular risk factor: current status. Eur Heart J 31: 2844-2853.

27. Hueston WJ, Pearson WS, 2004 Subclinical hypothyroidism and the risk of hypercholesterolemia. Ann Fam Med 2: 351-355.

28. Imaizumi M, Akahoshi M, Ichimaru S, et al, 2004 Risk for ischemic heart disease and all-cause mortality in subclinical hypothyroidism. J Clin Endocrinol Metab 89: 3365-3370.

29. Lee WY, Suh JY, Rhee EJ, et al, 2004 Plasma CRP, apolipoprotein A-1, apolipoprotein B and Lpa levels according to thyroid function status. Arch Med Res 35: 540-545.

30. Pirich C, Mullner M, Sinzinger H, 2000 Prevalence and relevance of thyroid dysfunction in 1922 cholesterol screening participants. J Clin Epidemiol 53: 623-629.

31. Arikan S, Bahceci M, Tuzcu A, Celik F, Gokalp D, 2012 Postprandial hyperlipidemia in overt and subclinical hypothyroidism. Eur J Intern Med 23: e141-145.

32. Hernandez-Mijares A, Jover A, Bellod L, et al, 2013 Relation between lipoprotein subfractions and TSH levels in the cardiovascular risk among women with subclinical hypothyroidism. Clin Endocrinol (Oxf) 78: 777-782.

33. Kolovou GD, Mikhailidis DP, Kovar J, et al, 2011 Assessment and clinical relevance of non-fasting and postprandial triglycerides: an expert panel statement. Curr Vasc Pharmacol 9: 258-270.

34. Kolovou GD, Mikhailidis DP, Nordestgaard BG, Bilianou H, Panotopoulos G, 2011 Definition of postprandial lipaemia. Curr Vasc Pharmacol 9: 292-301.

35. Mikhailidis DP, Elisaf M, Rizzo M, et al, 2011 "European panel on low density lipoprotein (LDL) subclasses": a statement on the pathophysiology, atherogenicity and clinical significance of LDL subclasses. Curr Vasc Pharmacol 9: 533-571.

36. Mikhailidis DP, Elisaf M, Rizzo M, et al, 2011 "European panel on low density lipoprotein (LDL) subclasses": a statement on the pathophysiology, atherogenicity and clinical significance of LDL subclasses: executive summary. Curr Vasc Pharmacol 9: 531-532.

37. Abbas JM, Chakraborty J, Akanji AO, Doi SA, 2008 Hypothyroidism results in small dense LDL independent of IRS traits and hypertriglyceridemia. Endocr J 55: 381-389.

38. Lai CC, Tang SH, Pei D, et al, 2011 The prevalence of subclinical thyroid dysfunction and its association with metabolic syndrome in Taiwanese elderly. Int J Geront 5: 25-29.

39. Park SB, Choi HC, Joo NS, 2011 The relation of thyroid function to components of the metabolic syndrome in Korean men and women. J Korean Med Sci 26: 540545.

40. Garduno-Garcia Jde J, Alvirde-Garcia U, Lopez-Carrasco $\mathrm{G}$, et al, $2011 \mathrm{TSH}$ and free thyroxine concentrations are associated with differing metabolic markers in euthyroid subjects. Eur J Endocrinol 163: 273-278.

41. Wang JY, Wang CY, Pei D, et al, 2012 Association between thyroid function and metabolic syndrome in elderly subjects. J Am Geriatr Soc 58: 1613-1614.

42. Wang CY, Chang TC, Chen MF, 2012 Associations between subclinical thyroid disease and metabolic syndrome. Endocr J 59: 911-917.

43. Canturk Z, Cetinarslan B, Tarkun I, et al, 2003 Hemostatic system as a risk factor for cardiovascular disease in women with subclinical hypothyroidism. Thyroid 13: 971-977.

44. Erem C, 2006 Blood coagulation, fibrinolytic activity and lipid profile in subclinical thyroid disease: subclinical hyperthyroidism increases plasma factor X activity. Clin Endocrinol (Oxf) 64: 323-329.

45. Erikci AA, Karagoz B, Ozturk A, et al, 2009 The effect of subclinical hypothyroidism on platelet parameters. Hematology 14: 115-117.

46. Fiarresga AJ, Feliciano J, Fernandes R, et al, 2009 Relationship between coronary disease and subclinical hypothyroidism: an angiographic study. Rev Port Cardiol 28: 535-543.

47. Gullu S, Sav H, Kamel N, 2005 Effects of levothyroxine treatment on biochemical and hemostasis parameters in patients with hypothyroidism. Eur J Endocrinol 152: 355-361.

48. Gunduz M, Gunduz E, Kircelli F, Okur N, Ozkaya M, 2012 Role of surrogate markers of atherosclerosis in clinical and subclinical thyroidism. Int $\mathrm{J}$ Endocrinol 2012: 109797.

49. Owen PJ, Rajiv C, Vinereanu D, et al, 2006 Subclinical hypothyroidism, arterial stiffness, and myocardial reserve. J Clin Endocrinol Metab 91: 2126-2132.

50. Peleg RK, Efrati S, Benbassat C, Fygenzo M, Golik A, 2008 The effect of levothyroxine on arterial stiffness and lipid profile in patients with subclinical hypothyroidism. Thyroid 18: 825-830.

51. Tian L, Gao C, Liu J, Zhang X, 2010 Increased carotid arterial stiffness in subclinical hypothyroidism. Eur $\mathbf{J}$ Intern Med 21: 560-563.

52. Toruner F, Altinova AE, Karakoc A, et al, 2008 Risk factors for cardiovascular disease in patients with subclinical hypothyroidism. Adv Ther 25: 430-437.

53. Yilmaz H, Ertugrul O, Ertugrul B, Ertugrul D, 2011 Mean platelet volume in patients with subclinical hypothyroidism. Platelets 22: 143-147. 
54. Danese MD, Ladenson PW, Meinert CL, Powe NR, 2000 Clinical review 115: effect of thyroxine therapy on serum lipoproteins in patients with mild thyroid failure: a quantitative review of the literature. J Clin Endocrinol Metab 85: 2993-3001.

55. Tanis BC, Westendorp GJ, Smelt HM, 1996 Effect of thyroid substitution on hypercholesterolaemia in patients with subclinical hypothyroidism: a reanalysis of intervention studies. Clin Endocrinol (Oxf) 44: 643-649.

56. Meier C, Staub JJ, Roth CB, et al, 2001 TSH-controlled L-thyroxine therapy reduces cholesterol levels and clinical symptoms in subclinical hypothyroidism: a double blind, placebo-controlled trial (Basel Thyroid Study). J Clin Endocrinol Metab 86: 4860-4866.

57. Razvi S, Ingoe L, Keeka G, et al, 2007 The beneficial effect of L-thyroxine on cardiovascular risk factors, endothelial function, and quality of life in subclinical hypothyroidism: randomized, crossover trial. J Clin Endocrinol Metab 92: 1715-1723.

58. Serter R, Demirbas B, Korukluoglu B, et al, 2004 The effect of L-thyroxine replacement therapy on lipid based cardiovascular risk in subclinical hypothyroidism. J Endocrinol Invest 27: 897-903.

59. Arinzon Z, Zuta A, Peisakh A, Feldman J, Berner Y, 2007 Evaluation response and effectiveness of thyroid hormone replacement treatment on lipid profile and function in elderly patients with subclinical hypothyroidism. Arch Gerontol Geriatr 44: 13-19.

60. Ganotakis ES, Mandalaki K, Tampakaki M, et al, 2003 Subclinical hypothyroidism and lipid abnormalities in older women attending a vascular disease prevention clinic: effect of thyroid replacement therapy. Angiology 54: 569-576.

61. Perez A, Cubero JM, Sucunza N, et al, 2004 Emerging cardiovascular risk factors in subclinical hypothyroidism: lack of change after restoration of euthyroidism. Metabolism 53: 1512-1515.

62. Monzani F, Caraccio N, Kozakowa M, et al, 2004 Effect of levothyroxine replacement on lipid profile and intima-media thickness in subclinical hypothyroidism: a double-blind, placebo-controlled study. J Clin Endocrinol Metab 89: 2099-2106.

63. Tagami T, Tamanaha T, Shimazu S, et al, 2010 Lipid profiles in the untreated patients with Hashimoto thyroiditis and the effects of thyroxine treatment on subclinical hypothyroidism with Hashimoto thyroiditis. Endocr J 57: 253-258.

64. Iqbal A, Jorde R, Figenschau Y, 2006 Serum lipid levels in relation to serum thyroid-stimulating hormone and the effect of thyroxine treatment on serum lipid levels in subjects with subclinical hypothyroidism: the Tromso Study. J Intern Med 260: 53-61.

65. Ito M, Arishima T, Kudo T, et al, 2007 Effect of levothyroxine replacement on non-high-density lipoprotein cholesterol in hypothyroid patients. J Clin Endocrinol Metab 92: 608-611.
66. Ito M, Kitanaka A, Arishima T, et al, 2012 Effect of L-thyroxine replacement on apolipoprotein B-48 in overt and subclinical hypothyroid patients. Endocr J 60: 65-71.

67. Cabral MD, Teixeira P, Soares D, et al, 2011 Effects of thyroxine replacement on endothelial function and carotid artery intima-media thickness in female patients with mild subclinical hypothyroidism. Clinics (Sao Paulo) 66: 1321-1328.

68. Duman D, Demirtunc R, Sahin S, Esertas K, 2007 The effects of simvastatin and levothyroxine on intima-media thickness of the carotid artery in female normolipemic patients with subclinical hypothyroidism: a prospective, randomized-controlled study. J Cardiovasc Med (Hagerstown) 8: 1007-1011.

69. Kong WM, Sheikh MH, Lumb PJ, et al, 2002 A 6-month randomized trial of thyroxine treatment in women with mild subclinical hypothyroidism. Am J Med 112: 348354.

70. Kowalska I, Borawski J, Nikolajuk A, et al, 2011 Insulin sensitivity, plasma adiponectin and sICAM-1 concentrations in patients with subclinical hypothyroidism: response to levothyroxine therapy. Endocrine 40: 95-101.

71. Paoli M, Bellabarba G, Velazquez E, et al, 1998 Sex steroids, lipids, and lipoprotein cholesterols in women with subclinical and overt hypothyroidism before and after L-thyroxine therapy. Clin Chim Acta 275: 81-91.

72. Kebapcilar L, Comlekci A, Tuncel P, et al, 2010 Effect of levothyroxine replacement therapy on paraoxonase-1 and carotid intima-media thickness in subclinical hypothyroidism. Med Sci Monit 16: CR41-47.

73. Caron P, Calazel C, Parra HJ, Hoff M, Louvet JP, 1990 Decreased HDL cholesterol in subclinical hypothyroidism: the effect of L-thyroxine therapy. Clin Endocrinol (Oxf) 33: 519-523.

74. Cappola AR, Ladenson PW, 2003 Hypothyroidism and atherosclerosis. J Clin Endocrinol Metab 88: 2438-2444.

75. Cappola AR, Fried LP, Arnold AM, et al, 2006 Thyroid status, cardiovascular risk, and mortality in older adults. JAMA 295: 1033-1041.

76. Rodondi N, Newman AB, Vittinghoff E, et al, 2005 Subclinical hypothyroidism and the risk of heart failure, other cardiovascular events, and death. Arch Intern Med 165: 2460-2466.

77. Hyland KA, Arnold AM, Lee JS, Cappola AR, 2013 Persistent subclinical hypothyroidism and cardiovascular risk in the elderly: the cardiovascular health study. $\mathrm{J}$ Clin Endocrinol Metab 98: 533-540.

78. Legrys VA, Funk MJ, Lorenz CE, et al, 2013 Subclinical hypothyroidism and risk for incident myocardial infarction among postmenopausal women. J Clin Endocrinol Metab 98: 2308-2317.

79. Razvi S, Shakoor A, Vanderpump M, Weaver JU, Pearce $\mathrm{SH}, 2008$ The influence of age on the relationship between subclinical hypothyroidism and ischemic heart 
disease: a metaanalysis. J Clin Endocrinol Metab 93: 2998-3007.

80. Walsh JP, Bremner AP, Bulsara MK, et al, 2005 Subclinical thyroid dysfunction as a risk factor for cardiovascular disease. Arch Intern Med 165: 2467-2472.

81. Triolo M, de Boer JF, Annema W, Kwakernaak AJ, Tietge UJ, Dullaart RP, 2012 Low normal free T4 confers decreased high density lipoprotein anti-oxidative functionality in the context of hyperglycemia. Clin Endocrinol (Oxf) 79: 416-423.

82. Erdem TY, Ercan M, Ugurlu S, et al, 2008 Plasma viscosity, an early cardiovascular risk factor in women with subclinical hypothyroidism. Clin Hemorheol Microcirc 38: 219-225

83. La Vignera S, Condorelli R, Vicari E, Calogero AE, Endothelial dysfunction and subclinical hypothyroidism: a brief review. J Endocrinol Invest 35: 96-103.

84. Sharma R, Sharma TK, Kaushik GG, et al, 2011 Subclinical hypothyroidism and its association with cardiovascular risk factors. Clin Lab 57: 719-724.

85. Otocka-Kmiecik A, Mikhailidis DP, Nicholls SJ, et al, 2012 Dysfunctional HDL: a novel important diagnostic and therapeutic target in cardiovascular disease? Prog Lipid Res 51: 314-324.

86. Ghasemi M, Mousavi SA, Rezvanian H, et al, 2010 Carotid intima-media thickness in subclinical hypothyroidism. Int J Stroke 5: 131-132.

87. Nagasaki T, Inaba M, Henmi Y, et al, 2003 Decrease in carotid intima-media thickness in hypothyroid patients after normalization of thyroid function. Clin Endocrinol (Oxf) 59: 607-612.

88. Gao N, Zhang W, Zhang YZ, Yang Q, Chen SH 2013 Carotid intima-media thickness in patients with subclinical hypothyroidism: a meta-analysis. Atherosclerosis 227: 18-25.

89. Taddei S, Caraccio N, Virdis A, et al, 2003 Impaired endothelium-dependent vasodilatation in subclinical hypothyroidism: beneficial effect of levothyroxine therapy. J Clin Endocrinol Metab 88: 3731-3737.

90. Shakoor SK, Aldibbiat A, Ingoe LE, et al, 2010 Endothelial progenitor cells in subclinical hypothyroidism: the effect of thyroid hormone replacement therapy. J Clin Endocrinol Metab 95: 319-322.

91. Bastenie PA, Vanhaelst L, Bonnyns M, Neve P, Staquet M 1971 Preclinical hypothyroidism: a risk factor for coronary heart-disease. Lancet 1: 203-204.

92. Tieche M, Lupi GA, Gutzwiller F, et al, 1981 Borderline low thyroid function and thyroid autoimmunity. Risk factors for coronary heart disease? Br Heart J 46: 202206.

93. Hak AE, Pols HA, Visser TJ, et al, 2000 Subclinical hypothyroidism is an independent risk factor for atherosclerosis and myocardial infarction in elderly women: the Rotterdam Study. Ann Intern Med 132: 270-278.

94. Heinonen OP, Gordin A, Aho K, et al, 1972 Symptomless autoimmune thyroiditis in coronary heart-disease.
Lancet 1: 785-786.

95. Gasparyan AY, Ayvazyan L, Mikhailidis DP, Kitas GD, 2011 Mean platelet volume: a link between thrombosis and inflammation? Curr Pharm Des 17: 47-58.

96. Yu YT, Ho CT, Hsu HS, et al, 2013 Subclinical hypothyroidism is associated with elevated high-sensitive C-reactive protein among adult Taiwanese. Endocrine [Epub ahead of print].

97. Haidara M, Mikhailidis DP, Yassin HZ, et al, 2011 Evaluation of the possible contribution of antioxidants administration in metabolic syndrome. Curr Pharm Des 17: 3699-3712.

98. Reddy VS, Gouroju S, Suchitra MM, et al, 2013 Antioxidant Defense in Overt and Subclinical Hypothyroidism. Horm Metab Res 45: 754-758.

99. Chung GE, Kim D, Kim W, et al, 2012 Non-alcoholic fatty liver disease across the spectrum of hypothyroidism. J Hepatol 57: 150-156.

100. Athyros VG, Tziomalos K, Daskalopoulos GN, Karagiannis A, Mikhailidis DP, 2011 Statin-based treatment for cardiovascular risk and non-alcoholic fatty liver disease. Killing two birds with one stone? Ann Med 43: 167-171.

101. Athyros VG, Tziomalos K, Gossios TD, et al, 2010 Safety and efficacy of long-term statin treatment for cardiovascular events in patients with coronary heart disease and abnormal liver tests in the Greek Atorvastatin and Coronary Heart Disease Evaluation (GREACE) Study: a post-hoc analysis. Lancet 376: 1916-1922.

102. Lioudaki E, Ganotakis ES, Mikhailidis DP, 2011 Liver enzymes: potential cardiovascular risk markers? Curr Pharm Des 17: 3632-3643.

103. Fabbrini E, Magkos F, Patterson BW, Mittendorfer B, Klein S, 2012 Subclinical hypothyroidism and hyperthyroidism have opposite effects on hepatic very-low-density lipoprotein-triglyceride kinetics. J Clin Endocrinol Metab 97: E414-418.

104. Athyros VG, Mikhailidis DP, Didangelos TP, et al, 2006 Effect of multifactorial treatment on non-alcoholic fatty liver disease in metabolic syndrome: a randomised study. Curr Med Res Opin 22: 873-883.

105. Nakajima Y, Yamada M, Akuzawa M, et al, 2013 Subclinical hypothyroidism and indices for metabolic syndrome in Japanese women: One year follow-up study. J Clin Endocrinol Metab 98: 3280-3287.

106. Asik M, Sahin S, Ozkul F, et al, 2013 Evaluation of epicardial fat tissue thickness in patients with Hashimoto thyroiditis. Clin Endocrinol 79: 571-576.

107. Katsiki N, Mikhailidis DP, Wierzbicki AS, 2013 Epicardial fat and vascular risk: a narrative review. Curr Opin Cardiol 28: 458-463.

108. Inal S, Karakoc MA, Kan E, et al, 2012 The effect of overt and subclinical hypothyroidism on the development of non-dipper blood pressure. Endokrynol Pol 63: 97-103.

109. Cai Y, Ren Y, Shi J 2011 Blood pressure levels in patients 
with subclinical thyroid dysfunction: a meta-analysis of cross-sectional data. Hypertens Res 34: 1098-1105.

110. Genest J, McPherson R, Frohlich J, et al, 2009 Canadian Cardiovascular Society/Canadian guidelines for the diagnosis and treatment of dyslipidemia and prevention of cardiovascular disease in the adult - 2009 recommendations. Can J Cardiol 25: 567-579.

111. Reiner Z, Catapano AL, De Backer G, et al, 2011 ESC/ EAS Guidelines for the management of dyslipidaemias: the Task Force for the management of dyslipidaemias of the European Society of Cardiology (ESC) and the European Atherosclerosis Society (EAS). Eur Heart J
32: 1769-1818.

112. Shin DH, Lee MJ, Kim SJ, et al, 2012 Preservation of renal function by thyroid hormone replacement therapy in chronic kidney disease patients with subclinical hypothyroidism. J Clin Endocrinol Metab 97: 2732-2740.

113. Rallidis LS, Fountoulaki K, Anastasiou-Nana M, 2012 Managing the underestimated risk of statin-associated myopathy. Int J Cardiol 159: 169-176.

114. Tseng FY, Lin WY, Lin CC, et al, 2012 Subclinical hypothyroidism is associated with increased risk for all-cause and cardiovascular mortality in adults. J Am Coll Cardiol 60: 730-737. 